\title{
A AVIAÇÃO DE SEGURANÇA PÚBLICA NO CONTEXTO CONSTITUCIONAL DO CÓDIGO BRASILEIRO DE AERONÁUTICA DE 1986
}

Ericka Luana Ferreira Ramos ${ }^{1}$ Alex Mena Barreto ${ }^{2}$

\section{RESUMO}

A segurança pública no Brasil é um tema constantemente em destaque devido às incessantes demandas que envolvem as instituições constitucionalmente responsáveis. Nela está inserida a aviação de segurança pública, baseada no Código Brasileiro de Aeronáutica, legislação instituída anteriormente à promulgação da Constituição Federal. Hoje, essa atividade é conduzida e desempenhada apensada à aviação geral, o que leva à condição de obrigatoriedade de registro das aeronaves na Agência Nacional de Aviação Civil - Anac, agência reguladora federal que normatiza e supervisiona a aviação civil no país, o que significa que, para toda e qualquer operação aérea de segurança pública, é necessária prévia autorização desta agência. Em 2018, com a publicação da lei do Sistema Único de Segurança Pública surgiram novas interpretações no que se refere à aviação de segurança pública, trazendo à tona, a carência de legislação afeta ao tema, em virtude das peculiaridades que apresenta. Nesse sentido, esse artigo teve como objetivo contextualizar a aviação de segurança pública face às adaptações constitucionais do Código Brasileiro de Aeronáutica de 1986 e ratificar a necessidade da inovação legal para amparar essa atividade tão importante, por meio de revisão teórica, com abordagem qualitativa, em busca de fundamentação para reforçar proposição de alteração legislativa. Portanto, como conclusão do estudo, reforçou-se a necessidade aperfeiçoamento da legislação de aviação no país, para aprimoramento da disciplina aplicável à aviação de segurança pública, sendo prioritário o acatamento das inovações introduzidas pelo Projeto de Lei do Senado no 248, de 2016, que busca aprovação para a instituição de Novo Código Brasileiro de Aeronáutica.

Palavras-chave: Aviação de segurança pública; Código Brasileiro de Aeronáutica; Sistema Único de Segurança Pública; Projeto de Lei do Senado.

\footnotetext{
1 1ํ Tenente do Corpo de Bombeiros Militar do Paraná, bacharel em Segurança Pública pela Academia Policial Militar do Guatupê e graduando em Direito pela Universidade Positivo, especialista em Engenharia de Gestão Contra Incêndio e Pânico e em Direito Constitucional. Email: erickalfr@hotmail.com

2 Major da Polícia Militar do Estado de São Paulo, bacharel em Ciências Policiais de Segurança e Ordem Pública, especialista em Gestão de Organização em Segurança Pública e Justiça Criminal e mestre em Ciências Policiais de Segurança e Ordem Pública pelo Centro de Altos Estudos de Segurança. Habilitado como Piloto Policial de helicópteros, Comandante de aeronaves AS350 e instrutor de voo. E-mail: mba.mena@gmail.com
} 


\title{
PUBLIC SAFETY AVIATION IN THE CONSTITUTIONAL CONTEXT OF THE BRAZILIAN CODE OF AERONAUTICS OF
}

\author{
1986
}

\begin{abstract}
Public security in Brazil is a topic constantly highlighted due to the incessant demands that involve the constitutionally responsible institutions. It includes public safety aviation, based on the Brazilian Aeronautical Code, legislation instituted prior to the promulgation of the Federal Constitution. Today, this activity is conducted and performed in connection with general aviation, which leads to the condition that aircraft registration is mandatory at the National Civil Aviation Agency - Anac, a federal regulatory agency that regulates and supervises civil aviation in the country, which means that, for any and all public security air operations, prior authorization from this agency is required. In 2018, with the publication of the Single Public Security System law, new interpretations emerged with regard to public security aviation, bringing to light, the lack of legislation affects the topic, due to the peculiarities it presents. In this sense, this article aimed to contextualize public safety aviation in view of the constitutional adaptations of the Brazilian Aeronautical Code of 1986 and to ratify the need for legal innovation to support this very important activity, through a theoretical review, with a qualitative approach, in search for reasons to reinforce the proposal for legislative change. Therefore, as a conclusion of the study, the need to improve the aviation legislation in the country was reinforced, in order to improve the discipline applicable to public safety aviation, with priority being given to the innovations introduced by the Senate Bill No. 248, of 2016, which seeks approval for the institution of the New Brazilian Aeronautical Code.
\end{abstract}

Keywords: Public safety aviation. Brazilian Aeronautics Code. Single Public Security System. Senate Bill. 


\section{INTRODUÇÃO}

A segurança pública no Brasil, uma das principais atribuições do Estado, é um tema constantemente em destaque devido às incessantes demandas que envolvem os órgãos elencados no artigo 144 da Constituição Federal de 1988 e integrantes do Sistema Único de Segurança Pública.

Nesse contexto está inserida a aviação de segurança pública, uma atuação que envolve o uso de aeronaves e funciona, nos moldes atuais, desde a década de 1980, baseada no Código Brasileiro de Aeronáutica - CBA, legislação essa instituída anteriormente à promulgação da Carta Magna, quando o legislador não vislumbrava a dimensão de evolução da atividade que hoje é tão importante para o país.

No presente momento, a aviação de segurança pública é conduzida e desempenhada por instituições de segurança pública e defesa civil, com sua situação diretamente apensada à aviação geral, o que leva à condição de obrigatoriedade de registro das aeronaves na Agência Nacional de Aviação Civil - Anac, uma agência reguladora federal responsável por normatizar e supervisionar a atividade de aviação civil no Brasil.

Isso significa que, para toda e qualquer operação aérea de segurança pública, seja por meio de aeronaves de polícia militar, administrativa, judiciária, de bombeiros militares e de defesa civil, é necessária a autorização prévia da Anac, além do cumprimento de requisitos pré-estabelecidos de acordo com a classificação da respectiva ação a ser executada.

No entanto, no ano de 2018, a lei de criação do Sistema Único de Segurança Pública trouxe em sua redação a previsão dos integrantes operacionais deste sistema e abriu caminho para novas interpretações no que se refere à aviação de segurança pública, trazendo à tona, novamente, a carência de legislação afeta à atividade em tela. 
Assim, esse artigo tem como objetivo contextualizar a aviação de segurança pública face às adaptações constitucionais do Código Brasileiro de Aeronáutica de 1986 e ratificar a necessidade da inovação legal para melhor amparo da atividade no país, por meio de revisão teórica e pesquisa de literatura, com abordagem qualitativa, em busca de fundamentação para reforçar proposição de alteração legislativa.

\section{DESENVOLVIMENTO}

De início, é importante fazer uma breve reflexão histórica sobre o surgimento da aviação mundial e sua célere evolução em função da necessidade de sua utilização para fins belicosos e comerciais. Segundo a autora Fajer (2009, p.22) "a história da aviação tem início em 23 de outubro de 1906, no campo de Bagatelle, Paris, França, quando Alberto Santos-Dumont conseguiu: taxiar, decolar, voar nivelado e pousar com um aparelho que se deslocava com recursos próprios".

A atividade aérea trouxe consigo o desenvolvimento de países como Alemanha e França e proporcionou avanço em áreas da engenharia, da ciência, do trabalho e do mercado. Em outro viés, a Primeira Guerra Mundial alavancou a indústria aeronáutica "marcando definitivamente a importância do poder aéreo, transformando os aviadores nos mais celebrados e heróis de guerra, plantando raízes no meio militar, transformando-o no principal formador de pilotos" (FAJER, 2009, p.23).

Em 13 de outubro de 1919 foi assinada, por 27 países, a Convenção Internacional sobre Navegação Aérea, conhecida como Convenção de Paris, que reconhecia o direito de cada país controlar seu espaço aéreo. Nos Estados Unidos da América, à mesma época, foi criada o NACA - "National Advisory Commite for Aeronautics", que sugeria ficar a cargo do governo federal dos respectivos países a responsabilidade e controle do licenciamento de pilotos, 
além da inspeção e certificação de aeronaves, e estabelecimento e manutenção de aeroportos (CROUCH, 2008 apud FAJER, 2009).

De acordo com Sa $(2018$, p.2) "a Convenção de Paris foi a primeira grande convenção multilateral no domínio do direito aéreo e constitui, através de seu texto e da experiência da sua aplicação, uma enorme contribuição na preparação da Convenção de Chicago de 1944", onde surgiu a Organização da Aviação Civil Internacional (OACl), responsável por instigar o desenvolvimento seguro e ordenado da aviação civil mundial.

Sa (2018, p.1) ainda coloca que "a Convenção de Paris, costuma-se dizer, foi a primeira a produzir uma Convenção Internacional para regular a aviação civil, ou seja, uma espécie de marco regulatório do Direito Aéreo Internacional.

Com a eclosão da Segunda Guerra Mundial, o conflito monopolizou, mais uma vez, o cenário da aviação e esse momento importante para confirmar a superioridade do poderio aéreo que, segundo Fajer (2009, p.24) "tornou possível desde o bombardeio estratégico até o reconhecimento e o apoio às tropas em terra, revelando-se também um veículo para armas capazes de um extermínio devastador".

\begin{abstract}
Ao longo da Segunda Guerra Mundial, a dimensão da autonomia de voo das aeronaves aumentou significativamente. Estas evoluções tecnológicas transpuseram-se para a aviação comercial, provocando igualmente uma diminuição substancial no tempo de voo e o aumento do número total de passageiros transportados, o que permitiu um fluxo crescente de rotas nacionais e internacionais, o que contribuiu para que a comunidade internacional estabelecesse um conjunto de "princípios e medidas tendentes a desenvolver a aviação civil internacional de maneira segura e ordenada" (SA, 2018, p.2).
\end{abstract}

Diante disso, foi visualizada a premente necessidade de regulamentação geral do transporte aéreo no mundo, de cargas e de pessoas, capaz de garantir questões básicas como segurança, continuidade e regularidade de prestação de serviço com qualidade, além da formulação de normas e legislações seguras juridicamente. 
No final do período da segunda guerra, mais precisamente em 1944, aconteceu então, como citado anteriormente, a Convenção de Chicago, por meio da qual originaram as normatizações e regulamentações internacionais de aviação civil. Nessa oportunidade, foram estabelecidos padrões e recomendações que proporcionaram, entre outros resultados, um desenvolvimento seguro e ordenado da aviação internacional.

Em consequência, à Convenção de Paris, seguiu-se - em grau de importância - a Convenção sobre Aviação Civil Internacional, em Chicago, em setembro de 1944. Cinquenta e dois países acataram o convite dos EUA, e compareceram à Convenção, que acabou por ser concluída em 7 de dezembro de 1944, composta de 96 artigos divididos em quatro partes: Navegação Aérea, Organização Internacional da Aviação Civil (OACl, ou ICAO, em inglês), Transporte Aéreo Internacional e disposições finais. Constitui atualmente a base do sistema de direito internacional regulando a aviação, constituindo, ao fim e ao cabo, nas palavras de Baganha, "a carta da aviação civil internacional", dada a sua quase "intemporalidade" (SA, 2018, p.1).

Nesse momento da história, o Brasil foi signatário da Convenção de Chicago, a qual foi recepcionada no ordenamento jurídico por meio do Decreto no 21.713 , de 27 de agosto de 1946, com a finalidade de atingir a maior uniformidade regulamentar possível. Hoje, pode-se dizer que, apesar de antiga com necessidade de inovações contemporâneas, essa convenção detém a base legislativa de todo o Direito Aéreo Internacional.

As pouquíssimas revisões sofridas pela Convenção (apenas 8 desde
sua entrada em vigor), assim como o elevadíssimo número de
estados participantes, que conta hoje com 192 membros, demonstra
a abrangência geográfica, a força política e institucional deste
diploma internacional, consolidando-a como a "carta magna" da
aviação civil internacional hodiernamente (SA, 2018, p.2).

A partir de então, na década de 50 foram criadas as primeiras aeronaves a jato, na década de 70 surgiram as aeronaves supersônicas e os sistemas de navegação automática, na década de 80 foram desenvolvidos sistemas de gerenciamento de voo eletrônicos, na década de 90 foram implementados sistemas digitais com modernos comandos (para a época) e sistemas de proteção inteligentes. 
Especificamente quanto à aviação brasileira pós Convenção de Chicago, que veio acompanhando as evoluções mundiais, é importante destacar alguns marcos regulatórios e históricos como o surgimento primeiros serviços aéreos policiais, hoje caracterizados como aviação de segurança pública, a elaboração do Código Brasileiro de Aeronáutica em 1986, a criação do Ministério da Defesa em 1999 e o advento da Agência Nacional de Aviação Civil em 2005.

Enquanto as regras internacionais sobre Aviação Civil ingressavam paulatinamente no ordenamento jurídico interno, à medida que os temas eram discutidos em encontros multilaterais, buscou-se, na legislação interna, a consolidação de um único documento, que expressasse a vontade de todas as normas extravagantes existentes concomitantemente com as já vigentes no País (BENI, 2009, p.28).

Voltando-se ao objetivo deste artigo, de contextualizar a aviação de segurança pública e ratificar a necessidade da inovação legal para melhor amparo de uma atividade, o Decreto ํㅡ 21.713, de 27 de agosto de 1946, que recepcionou os normativos da Convenção de Chicago, define, em seus princípios gerais, sua aplicação exclusivamente a aeronaves civis, conforme segue:

Artigo $3^{\circ}[\ldots]$

Esta Convenção será aplicável unicamente a aeronaves civis, e não a aeronaves de propriedades do Governo; (BRASIL, 1946).

O mesmo texto legal, após delimitar a aplicação supra, define o que são aeronaves de propriedade do Governo:

Artigo $3^{\circ}[\ldots]$

São consideradas aeronaves de propriedade do Governo aquelas usadas para serviços militares, alfandegários e policiais; (BRASIL, 1946).

Analisando o contexto desta legislação que regulamenta a aviação civil internacional e que foi recepcionada pelo ordenamento jurídico brasileiro, podese perceber claramente que, além de se encontrar em plena vigência, ainda 
define, de forma igualitária, as aeronaves usadas para serviços militares, serviços alfandegários e serviços policiais.

Esse formato de definição, aeronaves civis e aeronaves públicas, é mundialmente aplicado na aviação, citando-se, a título de referência, os Estados Unidos, a Colômbia e a Alemanha. No Brasil, o direito aeronáutico é regulado pelos Tratados, Convenções e Atos Internacionais de que o Brasil seja parte, pelo Código Brasileiro de Aeronáutica e pela legislação complementar.

Nesse contexto, não restam dúvidas quanto à inserção de aeronaves militares e policiais no rol da aviação pública. Entretanto, em que pese o uso explícito do termo "aeronave policial" na Convenção de Chicago, todos os diplomas legais brasileiros são omissos em relação à aviação de segurança pública e fazem menção apenas à aviação militar.

Fato é que o ordenamento jurídico brasileiro possui carência de legislação específica em aviação de segurança pública e diante dessa omissão do legislador, para todos os fins, considera-se que esta é composta pelas aeronaves pertencentes aos órgãos públicos previstos no artigo 144, da Constituição Federal, conforme segue:

\footnotetext{
Art. 144. A segurança pública, dever do Estado, direito e responsabilidade de todos, é exercida para a preservação da ordem pública e da incolumidade das pessoas e do patrimônio, através dos seguintes órgãos:

I - polícia federal;

II - polícia rodoviária federal;

III - polícia ferroviária federal;

IV - polícias civis;

$\mathrm{V}$ - polícias militares e corpos de bombeiros militares.

$\mathrm{VI}$ - polícias penais federal, estaduais e distrital.
}

No entanto, importante se faz considerar que a novel Lei oㅜ 13.675, de 11 de junho de 2018, que instituiu o Sistema Único de Segurança Pública (Susp), prevê em seu artigo 9ำ quem são os integrantes operacionais do Susp e tal fato pode trazer novas interpretações referentes aos órgãos que compõem a aviação de segurança pública: 


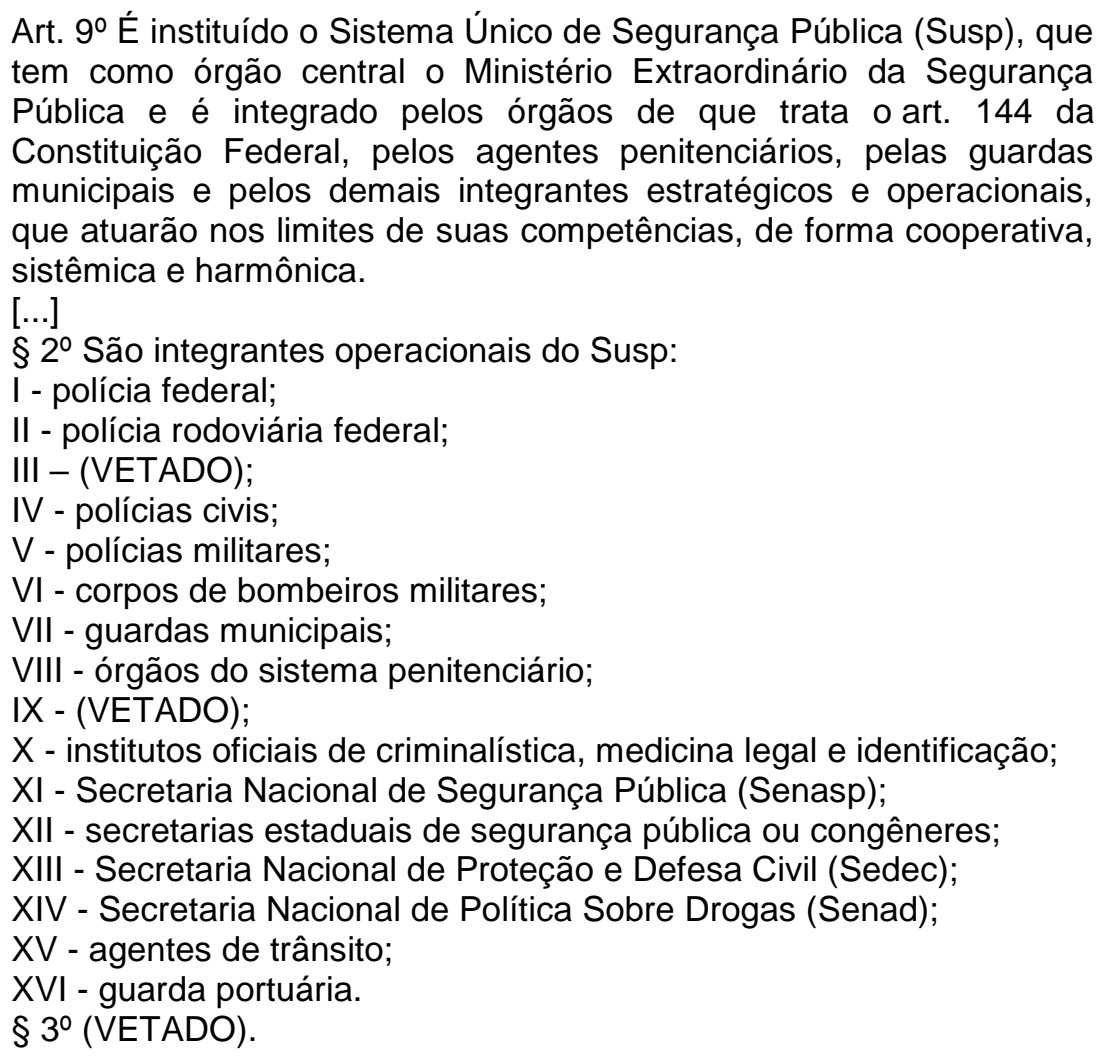

Todavia, atualmente, a Lei ㄲo 7.565, de 19 de dezembro de 1986 Código Brasileiro de Aeronáutica é o principal diploma legislativo do Direito Aeronáutico, sendo este de competência privativa da União. Cabe ressaltar que este Código foi tratado à luz dos preceitos instituídos pela Convenção sobre Aviação Civil Internacional, recepcionada pelo Brasil, e, não obstante tratar de normas de aplicação internacional, respeitaram em parte as regras instituídas por seu artigo 3으, citado anteriormente neste estudo (BENI, 2009).

Com o advento da Constituição Federal de 1988, algumas regras apresentadas nas Constituições anteriores foram mantidas, como por exemplo, a previsão constitucional do artigo 22, inciso I, determinado competência à União legislar sobre direito aeronáutico; ao Congresso Nacional, conforme artigo 48, inciso V, competência para delimitar os limites do espaço aéreo e marítimo e à lei, conforme o artigo 178, dispor sobre a ordenação do transporte aéreo e, aqui, conforme os preceitos da Carta Magna, o Código Brasileiro de Aeronáutico ter sido recepcionado por ela (BENI, 2009, p.28). 
Em decorrência do Código Brasileiro de Aeronáutica (CBA), estabeleceu-se o Regulamento Brasileiro de Homologação Aeronáutica como instrumento para regulamentar a lei em diversos assuntos, principalmente quanto ao Sistema de Segurança de Voo, Sistema de Formação e Adestramento de Pessoal, Serviços Auxiliares, Nacionalidade, Matrícula e Aeronavegabilidade, Serviços Aéreos e Responsabilidade Civil, mas, na oportunidade, não foram contemplados os serviços executados diretamente pelo Poder Público.

O artigo 107 do CBA traz em seu texto o seguinte:

Art. 107. As aeronaves classificam-se em civis e militares.

$\S 1^{\circ}$ Consideram-se militares as integrantes das Forças Armadas, inclusive as requisitadas na forma da lei, para missões militares (artigo $3^{\circ}, \mathrm{I}$ ).

$\S 2^{\circ}$ As aeronaves civis compreendem as aeronaves públicas e as aeronaves privadas.

$\S 3^{\circ}$ As aeronaves públicas são as destinadas ao serviço do Poder Público, inclusive as requisitadas na forma da lei; todas as demais são aeronaves privadas.

$\S 4^{\circ}$ (Revogado pela Lei oㅜ 12.887, de 2013)

$\S 5^{\circ}$ Salvo disposição em contrário, os preceitos deste Código não se aplicam às aeronaves militares, reguladas por legislação especial (artigo 14, § $6^{\circ}$ ).

Diante da omissão, para suprir tal lacuna, as demais atividades de aviação executadas pelo poder público foram regulamentadas por instrumentos normativos não primários, aplicando-se à aviação de segurança pública as mesmas regras da aviação civil. Ora, é incompreensível o fato de órgãos pertencentes ao mesmo poder estatal e em atividades de segurança e defesa da população, terem tratamentos distintos, como se pessoas jurídicas de direito privado fossem.

A lei não só se omitiu na definição das atividades desenvolvidas pelos órgãos de segurança pública, como também não estabeleceu previsão referente à infraestrutura, formação, licenças, aplicação de taxas, dentre outras.

O CBA limita sua competência quanto a sua aplicação sobre aeronaves militares e sobre atividades exclusivas das Forças Armadas e não prevê a Aviação de Segurança Pública, diferente das anteriores que, apesar de não dizerem especificamente sobre esta 
atividade pública de aviação, permitiam os serviços executados diretamente pelo Estado e previam algumas exceções às suas aeronaves (BENI, 2009, p.29).

De todo modo, o Código Brasileiro de Aeronáutica apresenta conceitos sobre aeronaves do Estado e há previsão de considerações específicas somente para as aeronaves militares, omitindo-se no que diz respeito às aeronaves públicas, destinadas ao serviço do poder público. Aqui, pode-se identificar possível inconstitucionalidade, pois ao considerar aeronaves públicas como aeronaves civis, no gênero, possibilita que a autoridade de aviação civil estenda, por analogia, as normas instituídas para a aviação civil aos serviços essenciais do Estado.

Por outro lado, a aviação militar, seguindo os preceitos da própria Convenção sobre Aviação Civil Internacional, possui normatização específica, o que leva a aplicação, tão somente, das regras gerais do CBA. Ora, se a aviação nas Forças Armadas é atividade de Estado e decorre de preceito constitucional, à aviação de segurança pública deveria, ser aplicados os mesmos preceitos jurídicos, uma vez que as especificidades da atividade, inclusive no plano constitucional, determinam normatização própria.

A tal observação, ainda pode ser acrescida do inconteste fato de que as Forças Auxiliares, militares estaduais, também compõem os órgãos de segurança pública e recepcionam, por equiparação, grande parte das legislações das Forças Armadas. É necessário compreender que não se busca equiparação de competências com as Forças Armadas, apenas a pura e simples regulamentação dos casos omissos na legislação brasileira, referentes à aviação de segurança pública.

Assim, com o passar dos anos, a aviação de segurança pública alcançou dimensões de trabalho que naturalmente não foram previstas na edição da legislação primária. Diante disso, mais do que em qualquer outra fase da história da aviação brasileira, se faz notória a necessidade de 
amadurecimento de previsão legislativa referente à essa atividade tão importante.

\section{CONCLUSÃO}

A aviação de segurança pública é um elemento importante e essencial na garantia da lei e da ordem, uma das principais atribuições do Estado, neste ato realizada por aeronaves pertencentes às instituições responsáveis pela segurança pública do país. Atualmente essa atividade está enquadrada na legislação da aviação geral, o que gera problemas e embates com relação à legitimidade de competências e atribuições.

Com a crescente demanda da atuação da aviação de segurança pública, de forma geral, o ordenamento carece de legislação específica que discipline a atividade levando em conta suas muitas particularidades, no sentido de sanar as lacunas que foram se formando ao longo do tempo e que o legislador, à época, não tinha condições de prever.

Nesse sentido, cabe dizer que o Código Brasileiro de Aeronáutica, por ser anterior à promulgação da Carta Magna, necessita sobremaneira de alteração e inovação legal. Mesmo que a legislação brasileira tenha recepcionado os normativos da Convenção de Chicago, não existe previsão que diga respeito à aviação de segurança pública, justamente porque seu surgimento foi posterior.

Em face disto, existe hoje, tramitando na Câmara dos Deputados, o Projeto de Lei do Senado o 258, de 2016, que instituiu o Novo Código Brasileiro de Aeronáutica, composto de 374 artigos e 12 Títulos. Este projeto é bastante robusto e abrange diversos assuntos, dentre eles a verificação de interesse público em ver reconhecidas algumas modificações a partir das necessidades da aviação da operação de aeronaves utilizadas pelas forças de segurança pública. 
Convergindo ao tema deste artigo, o interesse se dá com relação à atualização e aperfeiçoamento do texto do artigo 144, que trata da classificação das aeronaves, civis e militares. Com efeito, a intenção da proposta é manter a continuidade do tratamento diferenciado, assim como é o caso das aeronaves militares, previsto no artigo 145, às aeronaves de segurança pública, e incluir nesse rol todos os integrantes operacionais do Susp, previstos na Lei $\mathrm{n}^{\circ}$. 13.675, de 2018.

Considerando que toda a matéria aeronáutica, atualmente prevista na Lei oㅡ 7.565 , de 19 de dezembro de 1986, consiste em legislação anterior à Constituição de 1988 e outras legislações pertinentes, mostrando-se desatualizada em vista das evoluções legais tecnológicas ocorridas, exsurge 0 interesse público na discussão e aprovação da matéria, considerando que nas últimas três décadas, desde a vigência do CBA, a aviação em geral passou por grandes mudanças, restando oportuna a atualização legal por meio da proposição do projeto de lei em tela.

Assim, é forçoso concluir que o que se busca a partir das sugestões elencadas na proposta do PLS no 248 , de 2016, é o aperfeiçoamento da legislação de aviação no país, para o aprimoramento da disciplina aplicável à aviação de segurança pública, sendo prioritário o acatamento das inovações introduzidas pelos artigos 144 e 145, se adequando assim às normas internacionais, que há muito tempo reconhecem a importância e as peculiaridades da aviação de segurança pública.

\section{REFERÊNCIAS}

BENI, Eduardo Alexandre. Aviação de Segurança Pública e a Responsabilidade Cível do Comandante de Aeronave da Polícia Militar do estado de São Paulo. 2009. Acesso: Disponível em: 
https://www.pilotopolicial.com.br/wp-content/uploads/2013/05/Monografia-CAPPM-BENI-CAO-I-09.pdf - 20 de maio de 2020.

BRASIL. Código Brasileiro de Aeronáutica. Lei no 7.565, de 19 de dezembro de 1986. Disponível em: http://www.planalto.gov.br/ccivil 03/leis/L7565.htm Acesso: 11 de maio de 2020.

Constituição da República Federativa do Brasil. Brasília: Senado, 1988. Disponível em: http://www.planalto.gov.br/ccivil 03/constituicao/constituicao.htm - Acesso: 11 de maio de 2020.

Regulamento Brasileiro de Homologação Aeronáutica. Disponível em: https://www.anac.gov.br/assuntos/legislacao/legislacao-1/rbha-e-rbac/rbha - Acesso: 20 de maio de 2020.

Sistema Único de Segurança Pública e Política Nacional de Segurança Pública e Defesa Social. Lei o 13.675, de 11 de junho de 2018. Disponível em: http://www.planalto.gov.br/ccivil 03/ Ato20152018/2018/Lei/L13675.htm - Acesso: 20 de maio de 2020.

. Decreto no 21.713, de 27 de agosto de 1946. Promulga a Convenção sobre Aviação Civil Internacional, concluída em Chicago a 7 de dezembro de 1944 e firmado pelo Brasil, em Washington, a 29 de maio de 1945. Disponível em: http://www.planalto.gov.br/ccivil 03/decreto/1930-1949/D21713.htm Acesso: 13 de maio de 2020.

FAJER, Marcia. Sistemas de investigação dos acidentes aeronáuticos da aviação geral: uma análise comparativa. 2009. Tese de Doutorado. Universidade de São Paulo. Disponível em: https://www.teses.usp.br/teses/disponiveis/6/6134/tde-14012010095713/publico/MarciaFajer.pdf - Acesso: 13 de maio de 2020.

SA, Marcial. A evolução do direito aéreo internacional e a Convenção de Chicago. 2018. Disponível em: https://jus.com.br/artigos/70448/a-evolucao-dodireito-aereo-internacional-e-a-convencao-de-chicago/2 - Acesso: 13 de maio de 2020. 